\title{
Спектры фотолюминесценции квантовых ям InAs/GalnSb/InAs в среднем ИК диапазоне
}

\author{
(C) В.В. Уточкин ${ }^{1,2}$, М.А. Фадеев ${ }^{1}$, С.С. Криштопенко ${ }^{3}$, В.В. Румянцев ${ }^{1,2}$, В.Я. Алешкин ${ }^{1,2}$, \\ А.А. Дубинов ${ }^{1,2}$, С.В. Морозов ${ }^{1,2}$, Б.Р. Семягин ${ }^{4}$, М.А. Путято ${ }^{4}$, Е.А. Емельянов ${ }^{4}$, \\ В.В. Преображенский ${ }^{4}$, В.И. Гавриленко ${ }^{1,2, \text { Ф }}$ \\ ${ }^{1}$ Институт фризики микроструктур Российской академии наук, \\ 603087 Нижний Новгород, Россия \\ ${ }^{2}$ Нижегородский государственный университет им. Н.И. Лобачевского, \\ 603950 Нижний Новгород, Россия \\ ${ }^{3}$ Laboratoire Charles Coulimb, CNRS \& Universite Montpellier, \\ 34095 Montpellier, France \\ ${ }^{4}$ Институт ффизики полупроводников им. А.В. Ржанова \\ Сибирского отделения Российской академии наук, \\ 630090 Новосибирск, Россия \\ ฯ E-mail: gavr@ipmras.ru \\ Поступила в Редакцию 15 апреля 2020 г. \\ В окончательной редакции 21 апреля 2020 г. \\ Принята к публикации 21 апреля 2020 г.
}

Исследованы спектры фотолюминесценции волноводных гетероструктур с квантовыми ямами $\mathrm{AlSb} / \mathrm{InAs} / \mathrm{GaInSb} / \mathrm{InAs} / \mathrm{AlSb}$, предназначенных для генерации излучения на межзонных переходах в среднем инфракрасном диапазоне. Обнаруженные спектральные линии сопоставляются с расчетами зонной структуры.

Ключевые слова:: квантовая яма, InAs/GaInSb, фотолюминесценция, волноводная гетероструктура.

DOI: $10.21883 /$ FTP.2020.09.49834.26

\section{1. Введение}

Край валентной зоны $\mathrm{GaSb}$ лежит выше по энергии, чем край зоны проводимости InAs, что позволяет в квантово-размерных структурах InAs/GaSb управлять (при изменении толщин слоев) шириной запрещенной зоны. В симметричных квантовых ямах (КЯ) $\mathrm{InAs} / \mathrm{Ga}(\mathrm{In}) \mathrm{Sb} / \mathrm{InAs}$ c $W$-образным профилем потенциала экстремумы зон находятся в Г-точке зоны Бриллюэна [1]. Такие структуры используются за рубежом для создания лазеров среднего ИК диапазона (см., например, [2]). $\mathrm{B}$ настоящей работе предпринята первая попытка получения стимулированного излучения в структурах, сконструированных и выращенных в России.

\section{2. Исследуемая структура}

Исследуемый образец был выращен методом молекулярно-лучевой эпитаксии на подложке $\mathrm{GaAs}(001)$ в ИФП СО РАН [3]. Активная часть структуры выращивалась на композитном буфере, состоящем из метаморфного буферного слоя $\mathrm{GaSb}$ толщиной 2.4 мкм (cp. c [4]), 10-периодной „сглаживающей“ сверхрешетки $\operatorname{AlSb}(2.5$ нм $) / \mathrm{GaSb}(2.5$ нм) и слоя $\mathrm{GaSb}$ толщиной 0.6 мкм. Далее выращивались 10 КЯ $\mathrm{AlSb}(10$ нм $)-\operatorname{InAs}(3.63$ нм)$\mathrm{Ga}_{0.65} \mathrm{In}_{0.35} \mathrm{Sb}(3.05 \mathrm{Hм})-\operatorname{InAs}(3.63 \mathrm{Hм})-\mathrm{AlSb}(10 \mathrm{нм})$. Толщины слоев InAs и $\mathrm{Ga}_{0.65} \mathrm{In}_{0.35} \mathrm{Sb}$ выбирались равными целому числу монослоев (МС) - 12 и $10 \mathrm{MC}$ соответственно. Поверх выращивался покрывающий слой $\mathrm{GaSb}$ толщиной 6 нм. Зонная структура, волновые функции (ВФ) электронов и дырок и матричные элементы операторов скорости для межзонных переходов рассчитывались в рамках 4-зонной модели Кейна [5]. При расчете для лучшего согласия с измеренными спектрами фотолюминесценции толщина слоев InAs была

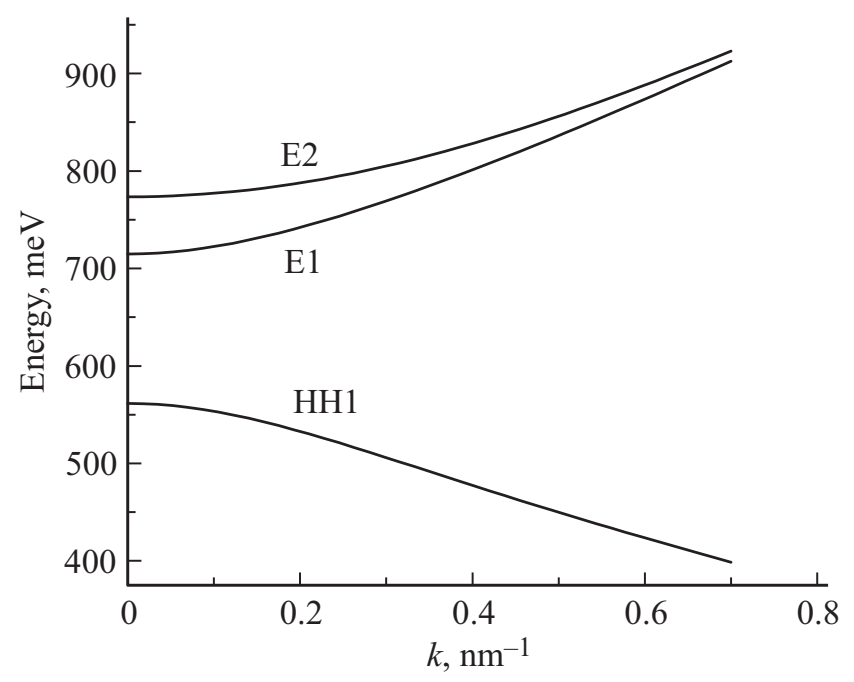

Рис. 1. Зонная структура КЯ в исследуемом образце, рассчитанная в рамках модели Кейна $8 \times 8$ [5]. 
уменьшена до $11 \mathrm{MC}$. Рассчитанная зонная структура КЯ представлена на рис. 1, а на рис. 2 представлено распределение модулей компонент ВФ в подзонах в КЯ
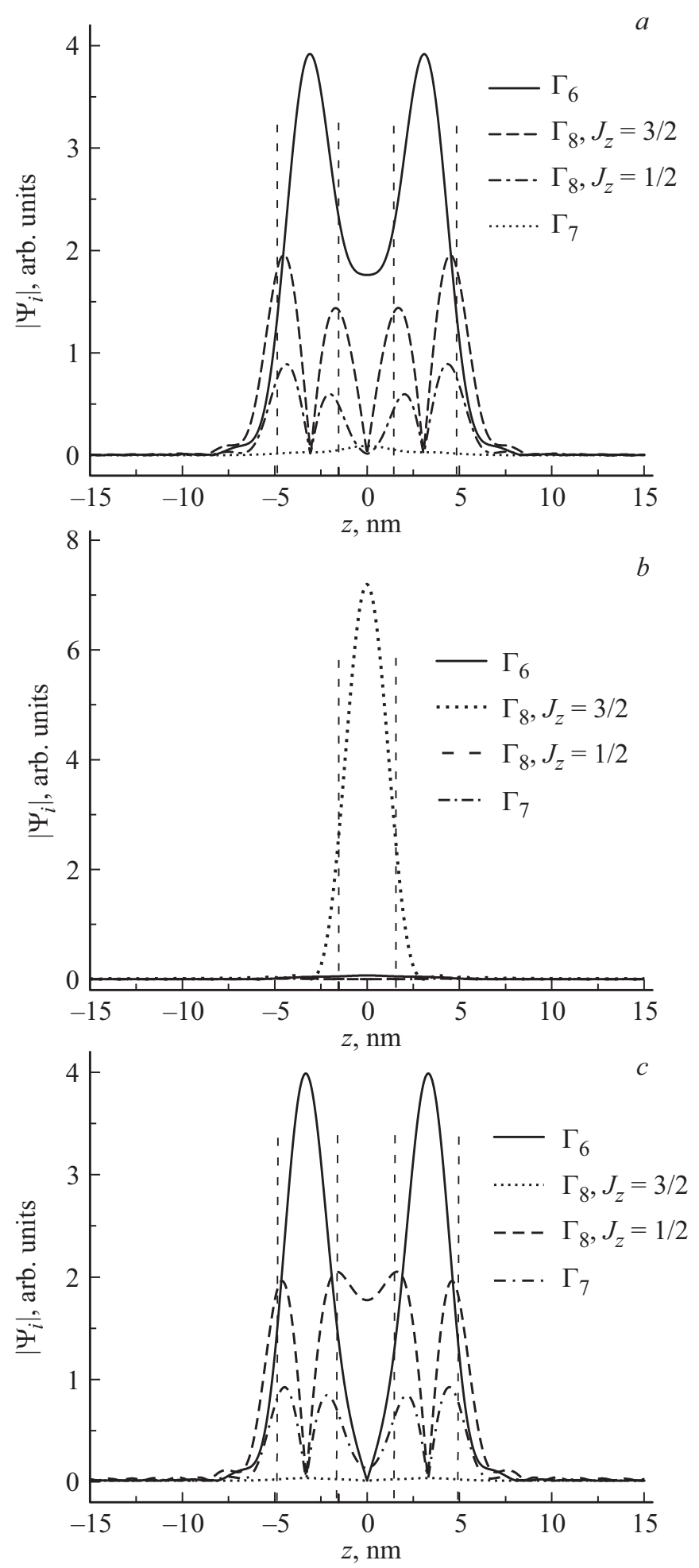

Рис. 2. Распределение модулей компонент ВФ в подзонах в КЯ в исследуемой структуре, соответствующих электронам $\left(\Gamma_{6}\right)$, легким дыркам $\left(\Gamma_{8}, J_{z}=1 / 2\right)$, тяжелым дыркам $\left(\Gamma_{8}, J_{z}=3 / 2\right)$, спин-отщепленным дыркам $\left(\Gamma_{7}\right): a-\mathrm{E} 1, b-\mathrm{HH} 1, c-\mathrm{E} 2$. Вертикальными линиями показаны границы слоев структуры.

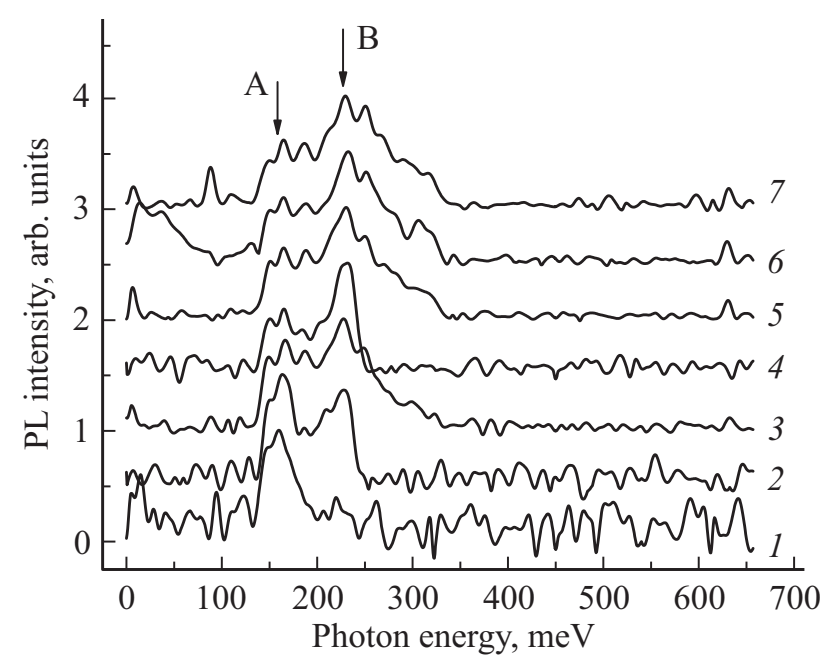

Рис. 3. Нормированные спектры ФЛ, измеренные при $T=10 \mathrm{~K}$ при различной средней мощности возбуждения, мВт: $1-3.5,2-14,3-35,4-44,5-51,6-65,7-80$.

в исследуемой структуре, соответствующих электронам (сплошные линии), легким дыркам (штриховые линии), тяжелым дыркам (пунктир), спин-отщепленным дыркам (штрихпунктир). Видно, что ВФ дырок (подзона НН1, рис. $2, b)$ практически полностью представлена состояниями $\Gamma_{8}, J_{z}=3 / 2$ (состояния тяжелых дырок) и локализована в центре КЯ, т.е. фактически в слое $\mathrm{GaInSb}$ и слабо проникает в слои InAs. 4-компонентные ВФ в подзонах $E_{1}$ и $E_{2}$ зоны проводимости представлены состояниями $\Gamma_{6}$ (электроны), $\Gamma_{8}, J_{z}=1 / 2$ (состояния легких дырок) и $\Gamma_{7}$ (состояния спин-отщепленной дырочной подзоны). Они локализованы соответственно в слоях InAs, но заметно проникают в слой GaInSb (вследствие малой эффективной массы электронов), что достигнуто за счет 35\%-й доли In в составе твердого раствора.

\section{3. Обсуждение результатов}

Спектры фотолюминесценции (ФЛ) измерялись с помощью фурье-спектрометра Bruker 80v в режиме пошагового сканирования при возбуждении излучением оптического параметрического осциллятора СОЛАР $\left(\lambda=2\right.$ мкм, $\tau_{\text {pulse }}=10 \mathrm{Hc}, f_{\text {rep }}=10$ Гц). Образец размером $5 \times 5$ мм располагался на холодном пальце в криостате замкнутого цикла. На рис. 3 представлены спектры ФЛ, измеренные при $T=10 \mathrm{~K}$. При минимальном уровне возбуждения в спектре наблюдается линия $A$, положение которой хорошо соответствует расстоянию между подзонами Е1 и НH1, с ростом интенсивности накачки возникает вторая линия $B$, положение которой соответствует расстоянию между второй электронной подзоной Е2 и НН1. Обе линии ФЛ наблюдались в спектрах вплоть до $T=110 \mathrm{~K}$ без заметного смещения по частоте при уменьшении интенсивности в несколько 


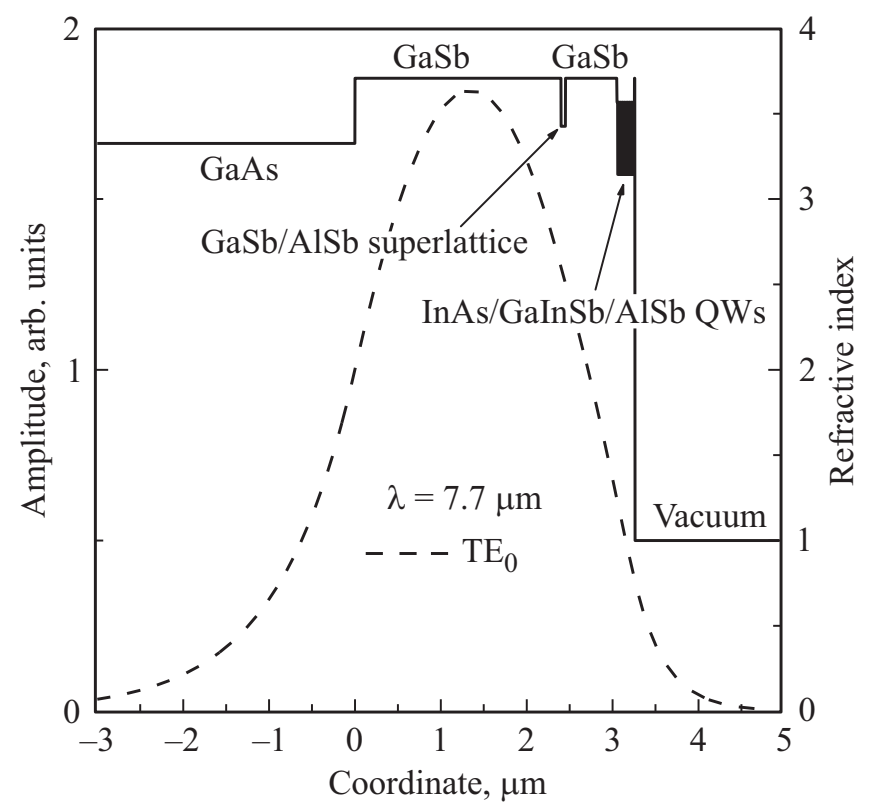

Рис. 4. Распределение показателя преломления и электрического поля ТЕ0 моды с длиной волны 7.7 мкм в исследуемой структуре.

раз, очевидно вследствие повышения вероятности безызлучательной рекомбинации.

Появление линии В спектрах люминесценции оказалось неожиданным. В „обычных“ КЯ оптические переходы из второй электронной подзоны Е2 в первую дырочную НН1 запрещены вследствие различной четности ВФ. Как видно из рис. 2, действительно, основная „электронная“ $\left(\Gamma_{6}\right)$ компонента ВФ в подзоне Е2 является нечетной, обращаясь в нуль в центре слоя $\mathrm{GaInSb}$, где максимальна ВФ тяжелых дырок в подзоне НH1. В то же время в подзоне Е2 четной является компонента ВФ, соответствующая легким дыркам $\left(\Gamma_{8}, J_{z}=1 / 2\right)$. Однако известно, что переходы между подзонами легких и тяжелых дырок возможны лишь при конечном значении квазиимпульса (запрещены при $k=0)$. Применительно к исследуемой структуре этот качественный вывод подтверждается расчетами квадратов матричных элементов оператора скорости для межзонных переходов. Так, для переходов $k=0$ эта величина составляет $\sim 5 \cdot 10^{30} \AA^{2} / \mathrm{c}^{2}$, в то время как для перехода Е2-НН1 при $k=0-\sim 4 \cdot 10^{25} \AA^{2} / \mathrm{c}^{2}$, т. е. на 5 порядков величины меньше. Оценка величины квадрата матричного элемента оператора скорости для перехода Е2-HН1 при конечном $k=0.26 \mathrm{HM}^{-1}$ дает величину $\sim 6 \cdot 10^{27} \AA^{2} / \mathrm{c}^{2}$, т. е. все равно на 3 порядка величины меньше, чем для перехода E1-HН1. При этом, чтобы состояния с таким волновым вектором в подзоне Е2 были заселены, подзона $E_{1}$ должна быть „залита“", как видно из рис. 1, до энергий $\sim 70$ мэВ, что привело бы к широкой полосе ФЛ на переходах E1-HН1, сливающейся с линией В, в то время, как видно из рис. 3 (кривая 2), при уровне возбуждения, когда линии А и В близки по интенсивности, они достаточно хорошо разрешены. По мнению авторов, это свидетельствует о том, что линиям А и В соответствуют оптические переходы с состояний дефектов, „привязанных“ к каждой из подзон E1 и Е2. Возбуждаемые межзонной подсветкой носители заряда захватываются на эти локализованные состояния, где их время жизни существенно превышает время рекомбинации зона-зона.

Как видно из рис. 3, повышение уровня накачки (до $\left.1.6 \mathrm{MBT} / \mathrm{cm}^{2}\right)$ не приводило к возникновению стимулированного излучения, несмотря на то что общая толщина структуры обеспечивала поддержание в ней волноводной моды TE0 (рис. 4). Как видно из рисунка, максимум волноводной моды находится в стороне от активной части структуры - области КЯ InAs/GaInSb/InAs. Для лучшей связи активной среды с волноводной модой в дальнейшем при „конструировании“ структур следует увеличить толщину слоя $\mathrm{GaSb}$ и „передвинуть“ КЯ в глубь волноводного слоя.

\section{4. Заключение}

В работе исследованы низкотемпературные спектры фотолюминесценции в среднем инфракрасном диапазоне гетероструктуры с „трехслойными“ квантовыми ямами InAs/GaInSb/InAs, ограниченными широкозонным полупроводником $\mathrm{AlSb}$, выращенной методом молекулярнолучевой эпитаксии на подложке $\mathrm{GaAs}(001)$. Выполнены расчеты энергетических спектров, волновых функций электронов и дырок и матричных элементов межзонных оптических переходов. В спектрах фотолюминесценции обнаружены две линии, положение которых соответствует расстояниям между первой (E1) и второй (E2) электронными подзонами и первой подзоной тяжелых дырок (HН1), при этом интенсивность высокочастотной линии растет с увеличением уровня оптического возбуждения. Появление высокочастотной линии связывается с захватом фотовозбужденных носителей на долгоживущие состояния дефектов, связанных с подзоной Е2, поскольку, как показывают проведенные расчеты, матричные элементы межзонных оптических переходов Е2-HН1 на несколько порядков меньше, чем для переходов E1-HН1. Электродинамические расчеты показывают наличие в структуре диэлектрического волновода, однако стимулированное излучение не наблюдалось вплоть до максимальных уровней накачки, поскольку квантовые ямы в исследуемой структуре оказались расположенными далеко от пучности волноводной моды ТЕ0.

\section{Финансирование работы}

Работа выполнена в рамках государственного задания Института физики микроструктур РАН (№ 0035-20190020) и при поддержке Российского фонда фундаментальных исследований (грант 18-42-520040_поволжье). 


\section{Конфликт интересов}

Авторы заявляют, что у них нет конфликта интересов.

\section{Список литературы}

[1] S.S. Krishtopenko, F. Teppe. Sci. Adv., 4, eaap7529 (2018).

[2] A.P. Ongstad, R. Kaspi, G.C. Dente, M.L. Tilton, R. Barresi, J.R. Chavez. Appl. Phys. Lett., 92, 141106 (2008).

[3] Е.А. Емельянов, Д.Ф. Феклин, А.В. Васев, М.А. Путято, Б.Р. Семягин, А.П. Василенко, О.П. Пчеляков, В.В. Преображенский. Автометрия, 47, 43 (2011).

[4] Yu.G. Sadofyev, A. Ramamoorthy, B. Naser, J.P. Bird, S.R. Johnson, Y.-H. Zhang. Appl. Phys. Lett., 81, 1833 (2002).

[5] С.С. Криштопенко, А.В. Иконников, К.В. Маремьянин, Л.С. Бовкун, К.Е. Спирин, А.М. Кадыков, М. Marcinkiewicz, S. Ruffenach, C. Consejo, F. Teppe, W. Knap, Б.P. Семягин, М.А. Путято, Е.А. Емельянов, В.В. Преображенский, В.И. Гавриленко. ФТП, 51, 40 (2017).

Редактор Г.А. Оганесян

\section{Photoluminescence spectra of InAs/GalnSb/InAs quantum wells in mid infrared range}

V.V. Utochkin ${ }^{1,2}$, M.A. Fadeev ${ }^{1}$, S.S. Krishtopenko ${ }^{3}$, V.V. Rumyantsev 1,2, V.Ya. Aleshkin 1,2, A.A. Dubinov ${ }^{1,2}$, S.V. Morozov ${ }^{1,2}$, B.R. Semyagin ${ }^{4}$, M.A. Putyato ${ }^{4}$,

E.A. Emelyanov ${ }^{4}$, V.V. Preobrazhenskii ${ }^{4}$,

V.I. Gavrilenko ${ }^{1,2}$

${ }^{1}$ Institute for Physics of Microstructures, Russian Academy of Sciences, 603087 Nizhny Novgorod, Russia

${ }^{2}$ Lobachevsky State University of Nizhny Novgorod, 603950 Nizhny Novgorod, Russia ${ }^{3}$ Laboratoire Charles Coulimb, CNRS \& Universite Montpellier, 34095 Montpellier, France

${ }^{4}$ Rzhanov Institute of Semiconductor Physics,

Siberian Branch of Russian Academy of Sciences, 630090 Novosibirsk, Russia

Abstract Photoluminescence spectra of waveguide AlSb/InAs/ $\mathrm{GaInSb} / \mathrm{InAs} / \mathrm{AlSb}$ quantum well heterostructures, intended for the radiation generation at interband transitions in mid infrared range, have been investigated. The observed spectral lines are compared with band structure calculations. 